\title{
Analysis of the role of the planetary boundary layer schemes during a severe convective storm
}

\author{
J. S. P. Wisse and J. Vilà-Guerau de Arellano \\ Meteorology and Air Quality Section, Wageningen University, Duivendaal 2, 6701 AP Wageningen, The Netherlands
}

Received: 16 June 2003 - Revised: 11 February 2004 - Accepted: 18 February 2004 - Published: 14 June 2004

\begin{abstract}
The role played by planetary boundary layer (PBL) in the development and evolution of a severe convective storm is studied by means of meso-scale modeling and surface and upper air observations. The severe convective precipitation event that occurred on 14 September 1999 in the northeast of the Iberian Peninsula was simulated by means of the mesoscale model MM5 (version 3) using three different PBL schemes. The numerical results show a large impact of the PBL schemes on the precipitation fields associated to the convective storm. The schemes are based on different physical assumptions: the nonlocal first order MediumRange Forecast (MRF) and Blackadar (BLA) scheme and the local, one-and-a-half order ETA scheme.
\end{abstract}

Surface and radar observations are used to validate the model results. The comparison focuses on three aspects: the evolution, the spatial distribution and the 24-h accumulated precipitation. The comparison with rain gauge observations shows that the MRF, BLA and ETA schemes predicted most of the precipitation during the morning, whereas the rain gauge stations recorded rainfall during the evening. The evaluation performed with the radar data shows that all three numerical simulations produced a realistic spatial accumulated precipitation distribution. According to the quantity distribution, all three numerical simulations were able to predict precipitation quantities comparable to the rain gauge measurements. The MRF scheme predicted the largest average accumulated precipitation and the largest average precipitation rate, whereas the ETA scheme predicted the smallest accumulated precipitation and average precipitation rate. However, the ETA scheme yielded the highest extreme precipitation rates.

The performance of the three schemes is analyzed in terms of the vertical distribution of potential temperature, specific humidity and conserved variables, like equivalent potential temperature and total water content. The MRF scheme showed more evidence of enhanced mixing than did the other

Correspondence to: J. Vilà-Guerau de Arellano

(jordi.vila@wur.nl) schemes. Due to this process, more moisture was more efficiently transported to the free atmosphere. Consequently, the MRF scheme predicts more widespread precipitation. Furthermore, the enhanced mixing led to a less sharp capping inversion. However, the stronger inversion resulting from suppressed mixing processes in the case of the ETA scheme yielded higher values of convective available potential energy (CAPE) than did the other two schemes. Consequently, the more extreme precipitation rates are simulated by MM5 when the ETA scheme is used.

Key words. Meteorology and atmospheric dynamics (mesoscale meteorology, convective processes, turbulence)

\section{Introduction}

Severe weather events with large amounts of precipitation (more than $200 \mathrm{~mm}$ ) in only one day normally occur once or twice a year in the northwestern part of the Mediterranean (Font, 1983). Due to the contrast between land and sea surface temperature (SST) and the land topography, these events often result in local flash floods that have a damaging impact on social and economic life. Climatic (Romero et al., 1998) and diagnostic (Ramis et al., 1994) studies have shown that most of these events have comparable synoptic settings and occur during the late summer and autumn. In addition to these studies, the large experimental field campaign Mesoscale Alpine Programme (MAP) has recently provided observational evidence to improve our understanding of the development and evolution of such systems on the Mediterranean basin and to study the influence of orography on the precipitation (Bougeault et al., 2001; Bougeault et al., 2003).

The intensity of a convective system strongly depends on the moisture and heat supply from the surface. The vertical transport of moisture and heat is determined by the physical characteristics of the planetary boundary layer (PBL). The PBL is normally described as the part of the troposphere 


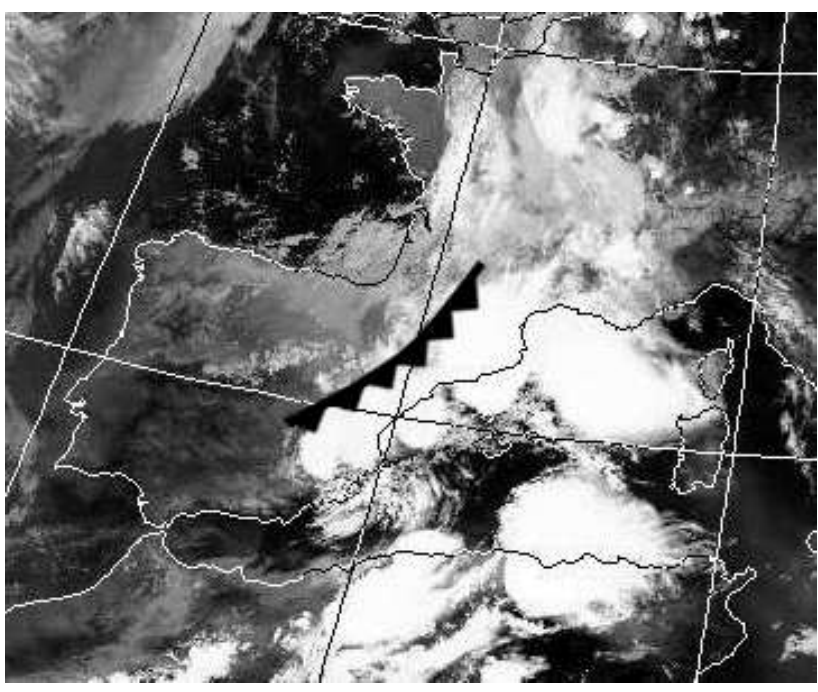

Fig. 1. The NOAA satellite image (channel 4, infrared) of the Iberian Peninsula shows the position of the cold front at 19:00 UT on 14 September 1999.

that is directly influenced by the Earth's surface, and it responds to surface forcings on a time scale of about one hour or less. In severe convective situations, however, this definition does not always hold. The vertical extension of the convection motions disrupts the whole troposphere and as a result, no clear PBL top can be distinguished. Therefore, other variables such as the cloudbase or lifting condensation level (LCL), are considered as the top of the PBL (Stull, 1999). In addition, deep convection largely alters the redistribution of heat and moisture from the surface into the upper layers.

Boundary layer processes are characterized by spatial and temporal scales smaller than the ones resolved explicitly by meso-scale models. Therefore, sub-grid parameterizations need to be applied to describe the vertical turbulent transport. Briefly, one can distinguish two approaches to represent the PBL in mesoscale models: local and nonlocal schemes. In the first approach, the flux of the variable at any point in space is calculated by variables and the gradients of known quantities at the adjacent levels. Local schemes are basically analogous to molecular diffusion. According to the second approach, the flux of the variable at one point is described by the values of known quantities at different points of the PBL. Turbulence is assumed to be a superpositioning of eddies, each of which transports fluid in the manner of an advection process.

Local and nonlocal boundary layer schemes implemented on mesoscale models have been mainly designed and evaluated for PBL developed under fair-weather conditions. Our main interest is to study the performance of these boundary layer schemes in severe weather situations. In particular, the impact of the local and nonlocal assumptions on cloudy boundary layers.

This paper reports on a sensitivity study of a convective precipitation event that occurred in Northeast Spain on

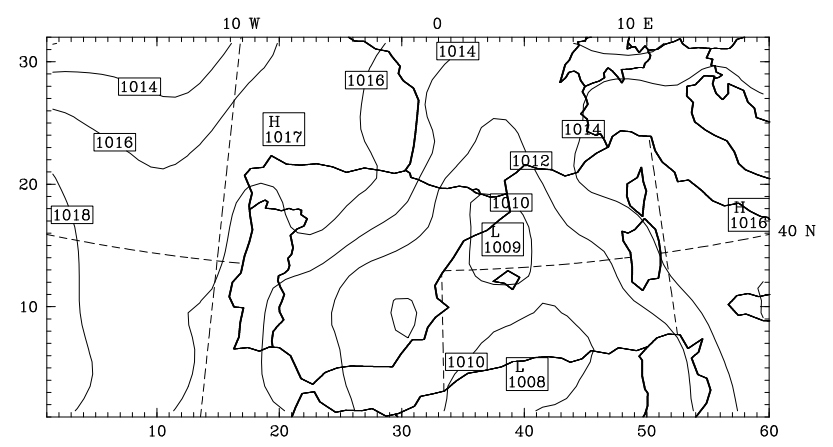

Fig. 2. The sea level pressure $(\mathrm{hPa})$ distribution of the convective situation at 19:00 UT on 14 September 1999.

14 September 1999 and describes the impact of various PBL parameterizations on such a meteorological phenomenon. In a different meteorological situation, Braun and Tao (2000) investigated the sensitivity of the simulation of hurricane Bob to various PBL schemes over the sea. This hurricane was characterized by high wind speeds and resulted in strong surface sensible and latent heat fluxes. Due to these large fluxes, the surface flux schemes played a major role in the supply of heat and moisture for the hurricane (Braun and Tao, 2000). Furthermore, our study includes two new important differences with respect to the study of Braun and Tao (2000): the contrast between the SST to land temperature and the presence of a complex topography.

Several model simulations studies have been performed for flash flood events in the northwestern Mediterranean. Romero et al. (2000) and Ferretti et al. (2000) showed that latent heat release in the convective system played an important role in the development of a surface meso-low and in consequence it contributed to extend the duration and intensified the precipitation. Ramis et al. (1998), Romero et al. (1997) and Ferretti et al. (2000) showed the importance of orography, since it serves to concentrate the precipitation in the coastal zone. Bechtold and Bazile (2001) have shown the high sensitivity of model results to modifications of the moisture content and SST for a flash flood situation reported in southern France. Moreover, they found that the parameterizations of convection and microphyisics have a large influence on the model convection characteristics. In the same region, Ferretti et al. (2003) compared high resolution model results with surface observations (pressure and 2-m temperature) and analyzed the disagreement between model results and measurements depending on the meteorological situation. Our work completes these previous studies by analyzing the role of boundary layer parameterizations in the development and intensification of a convective system.

In our study we compared various simulations in which only the PBL parameterizations had been changed in order to analyze whether they could predict the evolution in time and the spatial distribution of the precipitation fields. The same land/surface and deep convection schemes were used in all the simulations. Although detailed observational evidence 


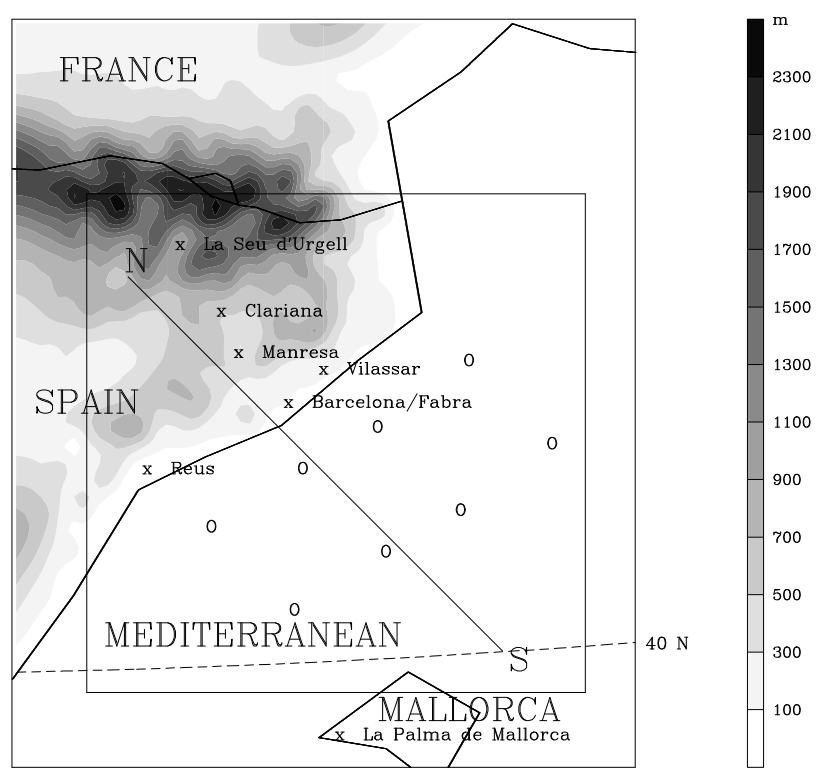

Fig. 3. Map of the third and inner domain. This map covers the northeastern part of the Iberian Peninsula and includes the topography of the region. The positions of the observations stations are marked with crosses and their respective names. The drawn square marks the area used to investigate the precipitation as calculated by the simulations (see Sect. 4). The circles over sea are the selected grid points used to investigate the various PBL variables (see Sect. 5). The line starting with $\mathrm{S}$ and ending with $\mathrm{N}$ indicates the direction and horizontal length of the vertical cross section discussed in Sect. 5.

is scarce, the results are compared with available rain gauge data, radar observations and radiosonde data. The discussion focuses on the evolution and distribution of the following variables: specific humidity, temperature, CAPE and LCL. The conserved variables, equivalent potential temperature $\left(\theta_{\mathrm{e}}\right)$ and the total water content are represented in thermodynamic diagrams. They enable us to determine the effect of entrainment and mixing of the various PBL schemes.

In Sect. 2 we describe the synoptic situation. Section 3 explains the numerical experiment. The comparison between the numerical results and observed precipitation is discussed in Sect. 4. There, we show the time evolution, the spatial pattern distribution and the accumulative precipitation fields. Section 5 provides an explanation of how the various physical assumptions used to develop the PBL parameterizations have an impact on variables related to convection.

\section{Synoptic situation}

On 14 September 1999 a severe convective system located at the NE of the Iberian Peninsula (IP) produced precipitation amounting to more than $100 \mathrm{~mm}$ (Fig. 1). According to McGinley (1986), in a synoptic environment, three basic conditions are necessary to produce such intense convective systems. Firstly, large-scale upward vertical motions

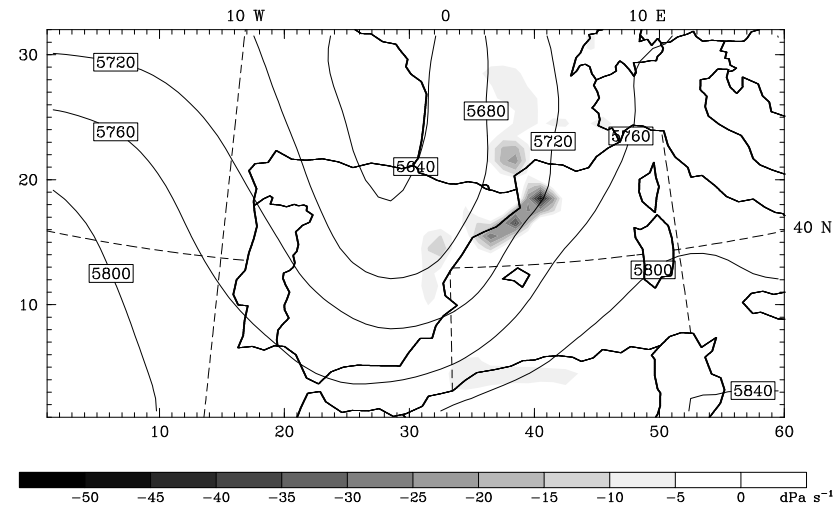

Fig. 4. Geopotential height (continuous line) and upward vertical motions (shaded area) at $500 \mathrm{hPa}$ at 19:00 UT.

are needed to trigger the initial development of a convective system. Secondly, moisture convergence in the lowest layer of the atmosphere must be present to feed the system with latent heat that will be released by condensation processes. Finally, an unstable stratification of the troposphere is necessary to permit individual air parcels to move vertically upwards. Below, these three aspects are analyzed for the case of 14 September 1999.

The total large-scale vertical motions were produced by a unique combination of mechanisms. During a period prior to 14 September 1999, a weak thermal low was well established above the center of the IP. On the day of interest, the low shifted slowly eastwards to the Mediterranean. As in comparable cases (for example, the case described by Romero et al., 2000) the generation of lee motions at the north of Algeria induced by upper air winds that crossed the Atlas Mountains intensified the weak thermal low. Figure 2 shows the air pressure distribution at 19:00 UT on 14 September. As is shown, a surface low centered north of Mallorca resulted in an enhanced onshore wind at the coast of Northeast Spain. According to Ramis et al. (1994), this surface pressure distribution is quite common during flash flood events in Northeast Spain. Figure 3 shows the orography in Northeast Spain. A steep chain of mountains runs parallel to the coastline. This orography forced the air transported by the onshore wind to ascend and therefore contribute to the largescale vertical motions over Northeast Spain.

Simultaneously, on 14 September, a trough intensified and shifted slowly eastwards, generating positive vorticity advection at $500 \mathrm{hPa}$ over Northeast Spain. This resulted in enhanced upward motions (Fig. 4). The upward vertical motions reached omega values of $-5 \mathrm{~Pa} \mathrm{~s}^{-1}\left(-50 \mathrm{dPa} \mathrm{s}^{-1}\right)$ at $500 \mathrm{hPa}$ which are comparable to upward vertical motions of approximately $0.5 \mathrm{~ms}^{-1}$. According to McGinley (1986) upward vertical motions smaller than $0.5 \mathrm{~ms}^{-1}$ are sufficient to trigger severe convective storms. Frontogenesis also helped to enhance the large-scale vertical motions that occurred just off the IP coast (Fig. 5). Besides depicting the convergence of the horizontal velocity (negative values of the divergence) close to the surface (approximately $50 \mathrm{~m}$ above the surface) 


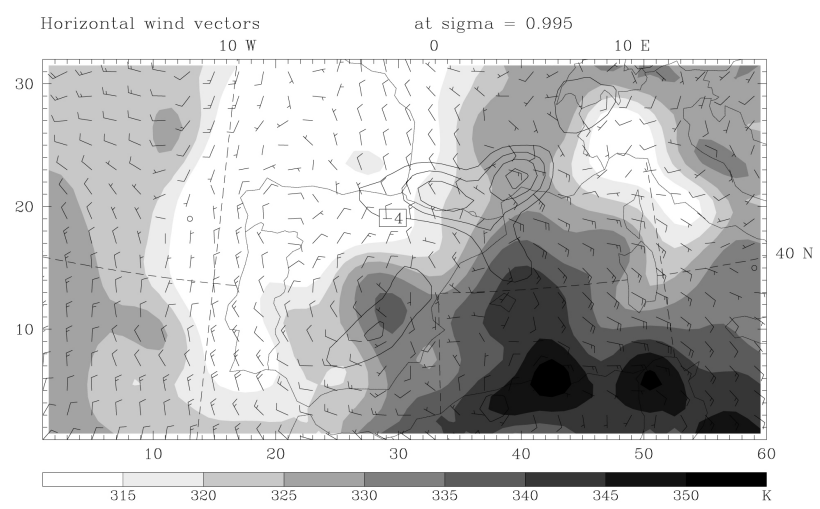

Fig. 5. The equivalent potential temperature at the lowest half model level ( $50 \mathrm{~m}$ above the surface), the divergence at the lowest half model level and the surface windbarbs at 19:00 UT on 14 September 1999. The shaded areas indicate the $\theta_{\mathrm{e}}$ horizontal distribution. The dashed contour lines reflect the horizontal negative divergence distribution smaller than $-4 \times 10^{-5} \mathrm{~s}^{-1}$ with a contour interval of $2 \times 10^{-5} \mathrm{~s}^{-1}$.

and the surface wind barbs, the figure shows the horizontal distribution of the equivalent potential temperature $\left(\theta_{\mathrm{e}}\right)$ near the surface. A sharp $\theta_{\mathrm{e}}$-gradient was present, representing the position of the frontal zone at surface level. This $\theta_{\mathrm{e}}$-gradient coincided with the large-scale frontal cloud band over the eastern part of the IP (see Fig. 1). The combination of the wind direction and the $\theta_{\mathrm{e}}$ distribution points clearly to cold air advection from the west, and warm and moist air advection from the east, as the surface wind bars indicated. This warm and cold air advection resulted in an enhancement of the $\theta_{\mathrm{e}}$ gradient. This enhancement resulted in frontogenesis and therefore contributed to the large-scale vertical motions.

Figure 6 shows the 24-h backward trajectories; these corroborate the different origin of the air at a different atmospheric level in Barcelona. The trajectories up to a level of $775 \mathrm{hPa}$ all originated in the southern part of the Mediterranean which still contained an SST of more than $25^{\circ} \mathrm{C}$. During the one-day journey of the air along the trajectories towards Barcelona, the relatively high SST enhanced the moisture content of the surface air masses (high $\theta_{\mathrm{e}}$ values), whereas at the upper level the air originated from the trough in the west and was therefore characterized by cold and dry air. This resulted in an unstable stratification with relatively high values of the dew point and air temperatures in the lower parts of the atmosphere and a relative low dew point and air temperatures in the upper parts of the atmosphere.

As a result of this interaction between the air masses, the atmosphere over the northeast part of the IP became very unstable. This atmospheric instability was also observed by the radiosonde. The most representative radiosonde for the area of Northeast Spain is the one launched at Palma de Mallorca $\left(39.5^{\circ} \mathrm{N}, 2.6^{\circ} \mathrm{E}\right.$, see Fig. 3). The vertical profiles of the dew point and air temperature extracted from this radiosonde launched at 12:00 UTC, 14 September 1999, are shown in Fig. 7. The gray shaded area represents the total positive

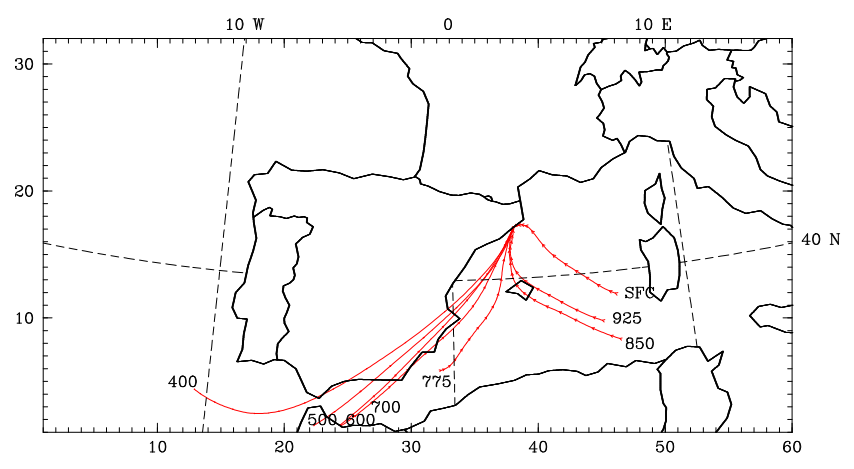

Fig. 6. 24-h backward trajectories for Barcelona (see Fig. 3) for 19:00 UT on 14 September 1999. These back trajectories started at 19:00 UT on 13 September 1999. Trajectories are marked with the atmospheric level ( $\mathrm{hPa}$ ) they reached in Barcelona (SRF: surface).

CAPE of an air parcel that is lifted from ground level up to the top of the atmosphere. According to this shaded area, the area of positive CAPE extended up to a level of $250 \mathrm{hPa}$, which made convection possible up to this level. The total positive CAPE was calculated according to:

$C A P E=g \int_{L F C}^{E L} \frac{\theta(z)-\bar{\theta}(z)}{\bar{\theta}(z)} d z$,

where $g$ is the gravity, $\theta(z)$ is the potential temperature of the air parcel, $\bar{\theta}(\mathrm{z})$ is the potential temperature of the environment and EL is the elevation level or the level to which a parcel is lifted up to. LFC is the level of free convection. Applying Eq. (1) to the vertical profile as shown in Fig. 7 resulted in a positive CAPE value of $1548 \mathrm{~J} / \mathrm{kg}$. This is a typical value for a moderately unstable atmosphere (Weisman and Klemp, 1986).

This observed radiosounding is also used to validate the MM5 model results at 12:00 UT at Palma de Mallorca (not shown). Shortly, the calculated model sounding shows a similar CAPE, unstable profile and wind shear in the tropsphere. The main difference between the observed and the calculated radisounding is in the location of the dry upper air level: $650 \mathrm{hPa}$ for the observed and $900 \mathrm{hPa}$ for the calculated.

Both the radiosonde taken at Mallorca and the trajectories show evidence of vertical (directional) shear. The winds in the lowest levels were weak with speeds of $5 \mathrm{~m} / \mathrm{s}$ and a southeasterly direction while the winds in the upper levels were strong with speeds of approximately $25 \mathrm{~m} / \mathrm{s}$ and a westerly direction. In addition to the ageostrophic circulations generated by the upper-level jet, Weisman and Klemp (1986) showed that this vertical shear can contribute to more severe convective systems.

Due to the key role played by the air mass close to the surface, it is therefore interesting to analyze the wind, temperature and moisture evolution of the PBL. The numerical experiments discussed in the next section analyzed this role 
and how the physical assumptions used to develop the studied PBL schemes influence the simulation of the convective cells.

\section{Description of the numerical experiment}

Version 3 of the non-hydrostatic Penn State University/National Center of Atmospheric Research Mesoscale Model (MM5) (Dudhia, 1993; Grell et al., 1995) was used to conduct a 48-h simulation of the above described severe precipitation event in Northeast Spain (00:00 UTC, 13 September-00:00 UTC, 15 September 1999). The second day was used to analyze and calculate the relevant variables. These results allowed us to investigate the impact of the PBL in such events.

Three different domains were defined. The coarse domain was defined by $60 \times 32$ grid points with a grid spacing of $45 \mathrm{~km}$. This domain covered the area from $5^{\circ} \mathrm{W}$ to $15^{\circ} \mathrm{E}$ and $36^{\circ} \mathrm{N}$ to $47^{\circ} \mathrm{N}$ (see Fig. 2). The second domain has $52 \times 55$ grid points with a grid spacing of $15 \mathrm{~km}$. This domain covered the area from $2^{\circ} \mathrm{W}$ to $8^{\circ} \mathrm{E}$ and $38^{\circ} \mathrm{N}$ to $44^{\circ} \mathrm{N}$. The third domain contained $76 \times 91$ grid points with a grid spacing of $5 \mathrm{~km}$. This fine-mesh domain is shown in Fig. 3 . The simulations used a one-way interactive nest between the coarse domain and the two smaller domains, and a two-way interactive nest between the second and third domain. The initial and boundary conditions were obtained from 6-hourly global analyses supplied by the European Center for Medium Range Weather Forecasts (ECMWF). We considered the first $24 \mathrm{~h}$ as a spin-up of the MM5 model, to take into account the increase in the grid length and the adjustment of the precipitation processes to the different cumulus parameterizations.

The number of vertical levels was set to 27 half- $\sigma$ levels, where $\sigma$ is defined as $\sigma=\left(p-p_{\text {top }}\right) /\left(p_{\text {sfc }}-p_{\text {top }}\right)$. Here, $p$ is the pressure, $p_{\text {sfc }}$ and $p_{\text {top }}$ are the pressures at the surface and the model top $(100 \mathrm{mb})$, respectively. Because this study focuses mainly on processes in the PBL, a relatively large number of half- $\sigma$ levels were prescribed in the PBL.

\subsection{Sensitivity analysis of the PBL schemes}

Three different numerical simulations, each using a different PBL scheme, were used to investigate the sensitivity of a simulated convective system to these schemes. From now on, these numerical simulations will designated according to the PBL scheme they used. The applied PBL schemes were: the Medium-Range Forecast scheme (MRF) (Hong and Pan, 1996; Troen and Mahrt, 1986), the High-Resolution Blackadar (BLA) scheme (Blackadar, 1976, 1979; Zhang and Anthes, 1982; Oncley and Dudhia, 1995) and the Eta-MellorYamada scheme (ETA) (Janjic, 1994). These schemes were selected because they are commonly applied in numerical weather forecast models or similar mesoscale models. However, they use different physical assumptions in order to calculate the vertical transport of momentum, heat and moisture. These differences will be briefly explained here.

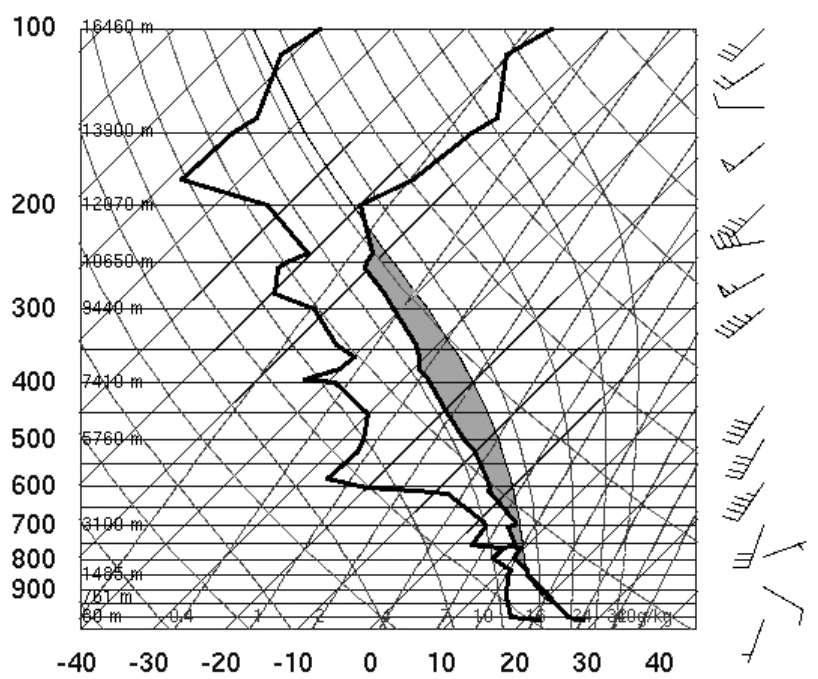

Fig. 7. Skew-T diagram representing the observations measured by the radiosonde launched at Palma de Mallorca at 12:00 UT on 14 September 1999 (provided and calculated by the University of Wyoming). The left thick line is the dew point temperature and the right thick line represents the temperature measurements. The shaded area is the total positive CAPE of an air parcel that is lifted up from the surface. The windbarbs reflect the observed wind direction and speed (half line $=5 \mathrm{kts}$ total line $=10 \mathrm{kts}$ and flag $=50 \mathrm{kts}$ ).

The development and maintenance of the PBL in a numerical model depends strongly on the parameterization of the surface fluxes. Briefly, in MM5, the surface sensible and latent heat fluxes are parameterized as:

$H_{s}=\rho_{a} c_{p} C_{\theta} V_{a}\left(\theta_{g}-\theta_{a}\right)$

$E_{s}=\rho_{a} L_{v} M C_{q} V_{a}\left[q_{v s}\left(T_{g}\right)-q_{a}\right]$,

where $c_{p}, L_{v}, M$ and $\rho_{a}$ are the specific heat, latent heat of vaporization of water, and the moisture ratio and air density at the lowest half- $\sigma$ level. $\theta_{g}$ and $q_{v s}$ are the potential temperature and the water vapor mixing ratio at surface level, where $q_{v s}$ is a function of the surface temperature $T_{g} . C_{\theta}$ and $C_{q}$ are the transfer coefficients for heat and water vapor. All three PBL schemes calculate the surface flux using Eqs. (2) and (3) but with different expressions for the coefficients $C_{\theta}$ and $C_{q}$. The MRF and BLA schemes use comparable expressions for $C_{\theta}$ and $C_{q}$. Therefore, these schemes are assumed to predict comparable surface fluxes. The expressions for $C_{\theta}$ and $C_{q}$ in the ETA scheme differ from those in the MRF and BLA schemes and are therefore expected to yield different surface fluxes. An important difference is that the ETA scheme assumes that $C_{\theta}=C_{q}$, whereas the MRF and BLA schemes prescribes that $C_{\theta} \neq C_{q}$.

Not only the surface fluxes but also the turbulent transport of heat and moisture throughout the convective PBL play an important role in the maintenance and development of the PBL. The MRF PBL mixing scheme is a nonlocal, first-order closure scheme. In the case of free convection, this scheme includes countergradient transport of heat and moisture. The 


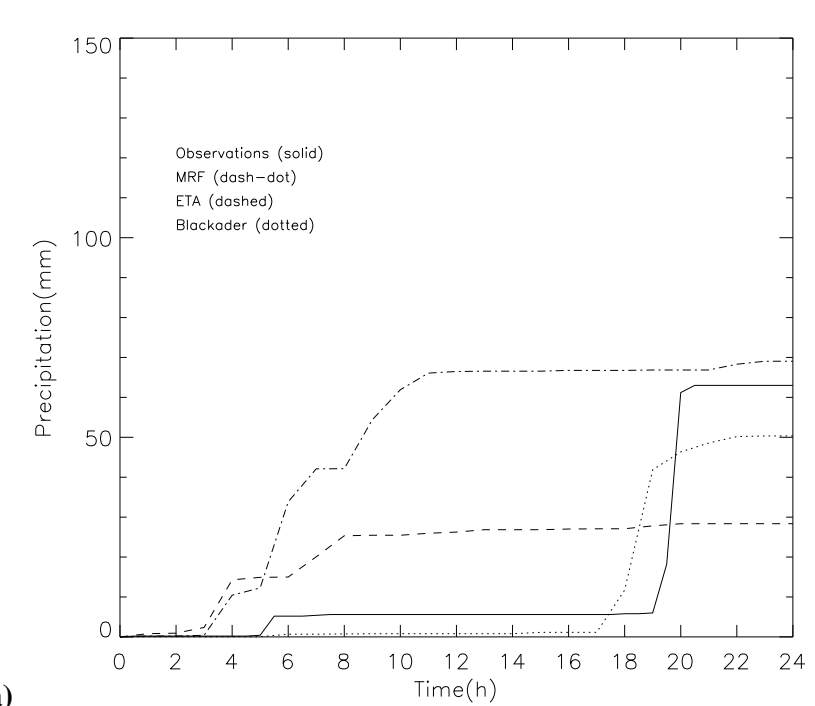

(a)

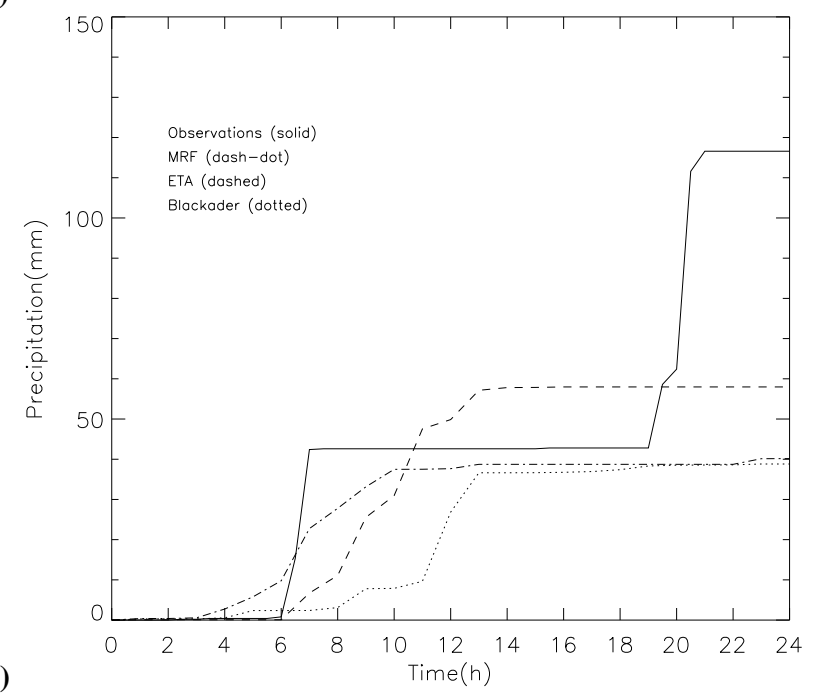

Fig. 8. Time evolution of the measured and calculated accumulated precipitation for 14 September 1999 at Fabra (a) and Vilassar (b) rain gauge stations. The observation (continuous line) are compared to the MRF (dash-dotted line), BLA (dotted line) and ETA (dashed line) PBL schemes.

vertical transport is based both on the gradient of the adjacent levels and on other PBL characteristics represented by bulk variables. This generally results in enhanced mixing and a better representation of the entrainment of dry and warm air from the free troposphere and therefore an enhanced growth of the PBL. Apart from the local vertical gradients, the MRF scheme includes an additional transport term for temperature $\left(\gamma_{h}\right)$ or moisture $\left(\gamma_{q}\right)$ to describe the contribution made by the large convective thermals to the vertical transport. This term accounts for the nonlocal effects. According to Priestely and Swinbank (1947) and Deardorff (1966), when the heat and the moisture flux incorporate these additional terms they become:

$\overline{w^{\prime} \theta^{\prime}}=-K_{h}\left(\frac{\partial \theta}{\partial z}-\gamma_{h}\right)$ $\overline{w^{\prime} q^{\prime}}=-K_{q}\left(\frac{\partial q}{\partial z}-\gamma_{q}\right)$.

Here, $\overline{w^{\prime} \theta^{\prime}}$ and $\overline{w^{\prime} q^{\prime}}$ are the kinematic heat and moisture fluxes, $\mathrm{K}_{h}$ and $\mathrm{K}_{q}$ are the eddy diffusivity coefficients for heat and moisture, $\theta$ is the potential temperature, and $q$ is the specific humidity. In the case of free convection $\gamma_{h}$ is approximately $1 \mathrm{~K}$ per $1000 \mathrm{~m}$ and $\gamma_{q} 1 \mathrm{~g} / \mathrm{kg}$ per $1000 \mathrm{~m}$.

Like the MRF, the BLA mixing scheme can be classified as a nonlocal scheme. In the regime of free convection, this scheme uses the air parcel method to describe the mixing processes in the PBL. According to this method an air parcel from the surface begins to rise when it experiences a higher temperature than its environment. Because the temperature of the air parcel is higher than that of the environment the air parcel experiences a positive CAPE. Finally, near the PBLtop, at the inversion, the air parcel will reach a level with equal temperature and from there onwards it will have negative CAPE. Air parcels will overshoot this level until the ratio of negative and positive CAPE of the air parcels is approximately 0.2 (Zhang and Anthes, 1982, see Fig. 2 in their paper). A fraction of air is exchanged at each level between the rising air parcel and the environment. In other words, the variables within the mixed layer are modified on the assumption that vertical exchanges take place between the lowest layer and each level of the mixed layer (Zhang and Anthes, 1982).

The ETA scheme is based on the one-a-and-half order turbulent closure scheme (Janjic, 1994). This scheme calculates the turbulent kinetic energy (TKE) prognostic equation and a master length to calculate the exchange coefficient for the turbulent fluxes (Mellor-Yamada level 2.5). The fluxes are derived using this exchange coefficient and the local gradients of temperature and moisture.

\subsection{Other physical options}

As mentioned before, other important physical processes were kept unchanged in all the simulations. Several tests were carried out to find out the most reliable set of these physical options. To parameterize cumulus processes, the Anthes-Kuo cumulus scheme (Anthes, 1977; Kuo, 1974) was applied in the coarse domain and the Grell cumulus scheme (Grell et al., 1995) was applied in the second domain. For the smallest domain, we carried out two different simulations to determine the sensitivity of the model to the cumulus parameterizations. In the first one, the Grell cumulus scheme was used and in the second one simulation, the cumulus convection is resolved explicitly. The model results were very similar. Therefore, no cumulus scheme was used in the domain with the highest horizontal resolution (Dudhia et al., 2000). Furthermore, the explicit solution of the cumulus clouds allowed us to study better the impact of the transport of heat and moisture in the convective systems without the interference of the selected cumulus pararameterization. If cumulus convection is parameterized, it can be a competition between the parameterized convective process and the turbulence generated at the boundary layer that can interfere in our 
analysis of the role of the boundary layer. A similar numerical experiment (no cumulus parameterization in the inner domain defined by a grid length of $4 \mathrm{~km}$ ) was set by Braun and Tao (2000), to study the effect of boundary layer representations in a hurricane. Finally, the simple ice scheme (Dudhia et al., 2000) was used to parameterize the microphysics. This scheme contains ice microphysics that are present in deep convective systems. The solar radiation was parameterized by using the cloud-radiation scheme (Dudhia et al., 2000). The land surface scheme used is the Five-Layer soil model (Dudhia, 1996).

\section{The effect of the PBL schemes on the precipitation fields}

Three different aspects were discussed in order to determine the effect of the different PBL schemes on the precipitation process: the time evolution, the spatial distribution patterns and the 24-h accumulated precipitation. Precipitation data derived from radar and rain gauge observations were used to validate model results.

The calculated precipitation was averaged hourly from the model results. Only the results obtained from the inner model domain are used in the discussion of the sensitivity of the simulation to the PBL scheme. The rain gauge observations are derived from half hourly precipitation measurements. The radar data were obtained from the radar located in Barcelona (see Fig. 3). The original radar reflectivity was used to calculate amounts of precipitation. The radar observations covered approximately the same area as the third inner domain.

\subsection{Evolution in time}

Figure 8 shows the accumulated precipitation distribution as predicted by the MRF, BLA and ETA simulations and as measured by the rain gauge stations: Fabra and Vilassar (see Fig. 3 for the location of these stations) on 14 September 1999. These two stations are positioned on the coast and are separated by about $25 \mathrm{~km}$. The rain gauge stations mainly observed precipitation during two brief episodes. The first episode occurred around 06:00 UT and the second event was around 19:00 UTC. Although the stations are relatively close to each other, the measured amounts were quite different. Fabra measured $3 \mathrm{~mm}$ during the morning episode (Fig. 8a) compared to $42 \mathrm{~mm}$ in Vilassar (Fig. 8b). During the evening Vilassar measured $76 \mathrm{~mm}$ compared to $62 \mathrm{~mm}$ in Fabra. The other rain gauge stations (no figure of the accumulated precipitation measured by these stations is shown in this paper) also showed temporal evolutions with short and intense precipitation episodes.

The above-mentioned differences in the temporal distribution of the precipitation between the different rain gauge stations are typical of the nature of severe convective storms. According to Atkinson (1981), these storms normally consist of separate active precipitation cells with a horizontal length scale of $3-5 \mathrm{~km}$ and a lifetime of $30-45 \mathrm{~min}$. This small time and length scale of convective systems, together with the complex topography of the area of Northeast IP resulted in precipitation events that were difficult to forecast on space and time.

The numerical simulations were not able to reproduce the measured time evolution of precipitation. All the simulations produced the main amount of precipitation during the morning hours. Only the numerical simulation using the BLA scheme predicted significant precipitation during the evening in the Fabra case. Furthermore, the calculated precipitation rates were lower and the simulated precipitation events extended over a longer period. These differences can be explained in two ways. Due to the localized character and small time scale of convective precipitation, a numerical model is unlikely to give an accurate quantitative description of the precipitation evolution over time. Secondly, the model averages the precipitation over the entire grid box, which is $25 \mathrm{~km}^{2}$ in the case of the finest-mesh domain. This averaging procedure yields generally lower precipitation rates and longer durations of the precipitation than do the rain gauge data, which are actually point measurements.

\subsection{Spatial distribution}

As stated by Saunders et al. (2001) it is better to compare the precipitation produced by a numerical model with the estimates derived from radar measurements than to use rain gauge data. This is because every radar image pixel, similar to the numerical model, describes the average precipitation of a certain area. Following the suggestion of Saunders et al. (2001), the spatial distribution of the accumulated precipitation produced by the numerical simulations was evaluated with radar data.

Figure 9 shows the accumulated precipitation for 14 September 1999 produced by the MRF, BLA and ETA numerical simulations and observed with the radar of Barcelona. The accumulated precipitation as shown by the radar picture is calculated from 10-min interval radar data and contains a grid cell area of $4 \mathrm{~km}^{2}$.

Over sea, the model simulations showed roughly the same accumulated spatial precipitation patterns as the radar image. The model simulations and the radar image both showed a precipitation area $\mathrm{A}$ that extended northwards towards the $\mathrm{B}$ region. The precipitation spot $\mathrm{C}$ in the model simulations is located more to the west than the radar image. The precipitation areas in the radar image, however, are less widespread. Due to the spatial patterns of the accumulated precipitation distribution over land derived from the radar data, it is difficult to find similar patterns in the model simulations. The main reason is the complex orography. Furthermore, the orography causes structural errors in the radar image because the presence of hills perturbed the radar observations, which results in an underestimation of the precipitation derived from the radar (Bader et al., 1995).

An intercomparison of the spatial accumulated precipitation distribution as predicted by MRF, BLA and ETA 


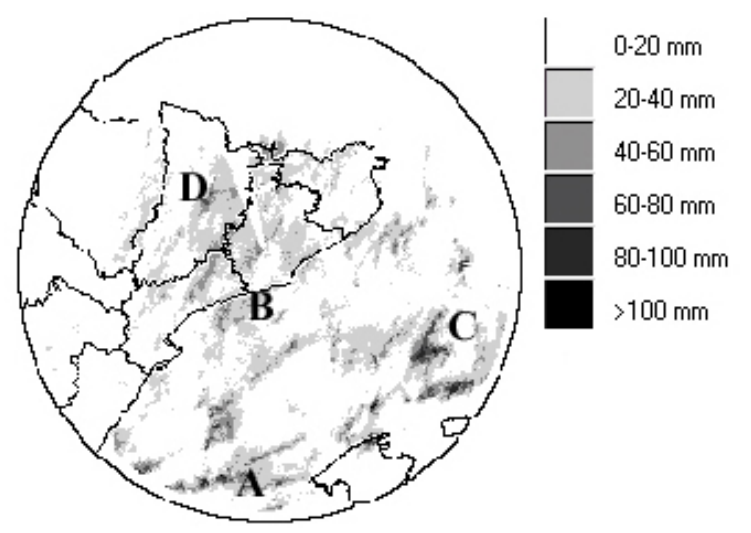

(a)

(c)

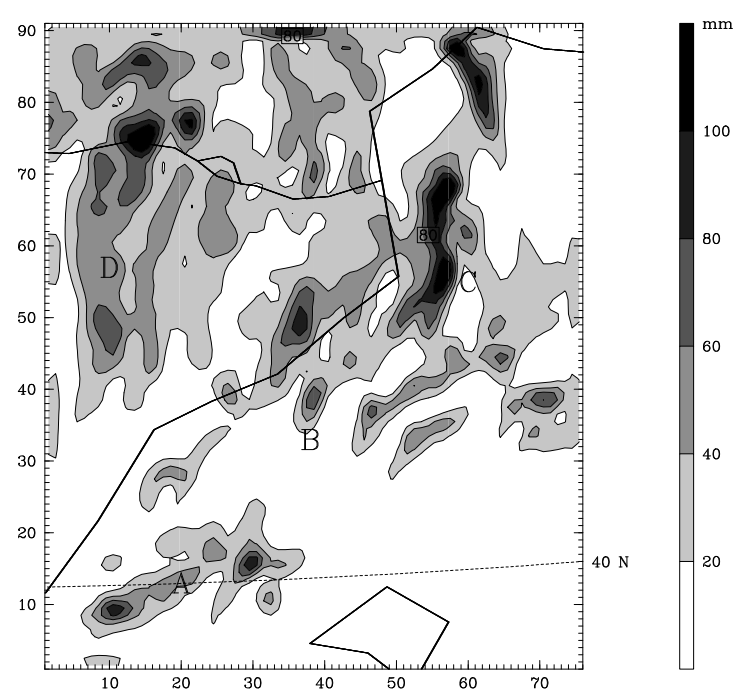

(b)

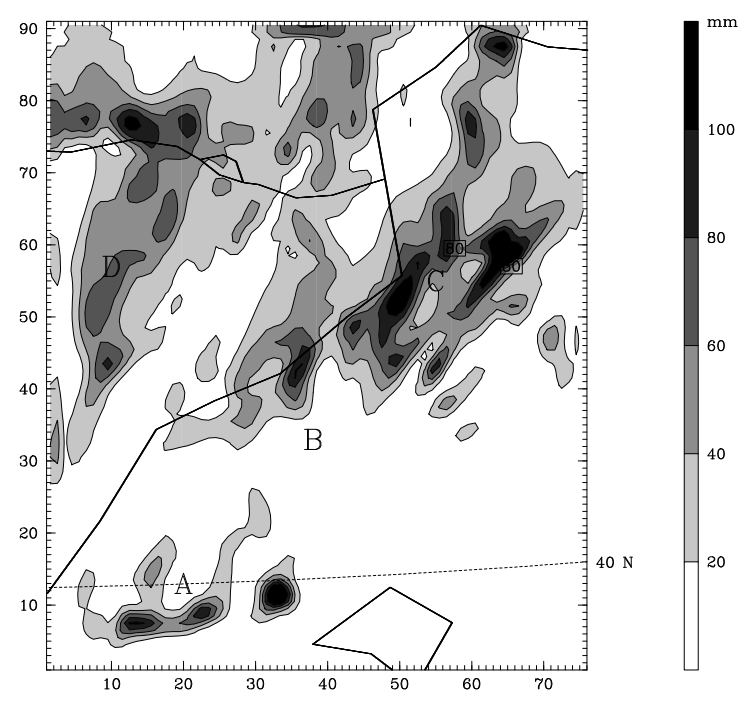

(d)

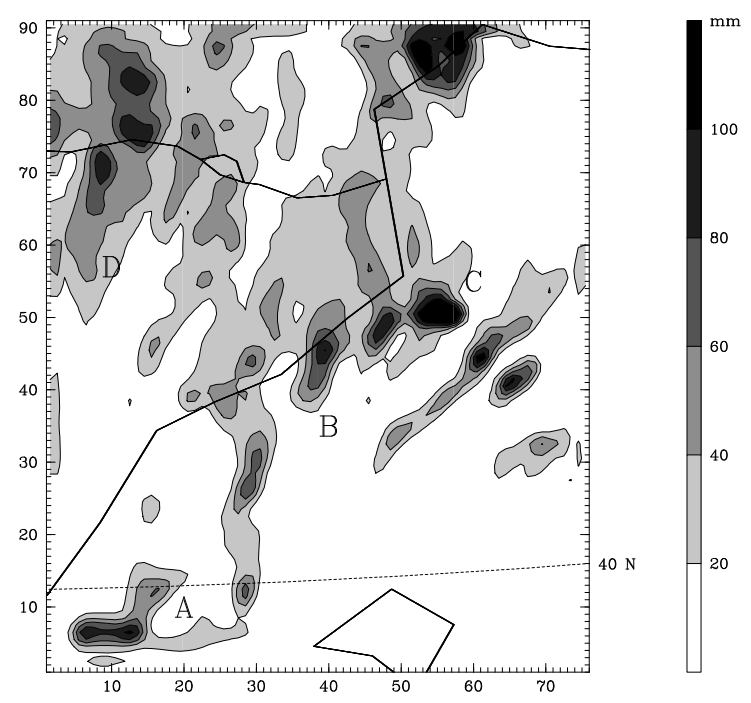

Fig. 9. 24-h accumulated precipitation for 14 September 1999. The most significant precipitation areas are indicated by the letters A, B, C and D. The panels correspond to the following observations and simulation: (a) Radar, (b) MRF, (c) BLA, (d) ETA.

numerical simulations show that the MRF numerical simulation yielded the largest area of precipitation (see Fig. 9). The MRF numerical simulation predicted more widespread precipitation particularly in regions $C$ and D. The ETA numerical simulation yielded the smallest area of precipitation. Braun and Tao (2000) also found that the MRF scheme yielded the largest area of precipitation in the numerical simulation of hurricane Bob.

\subsection{4-h accumulated precipitation and precipitation rates}

To analyze the precipitation distribution of 14 September 1999 quantitatively, we compare the 24-h accumulated precipitation and precipitation rates measured by radar and the rain gauge stations to the calculated by the MRF, BLA and ETA numerical simulations. Table 1 shows a statistical summary of the 24-h accumulated precipitation and the precipitation rates as calculated by MM5 and those observed with the radar. The 24-h accumulated precipitation statistics from the model results were based on 900 grid cells in a square of $300 \times 300 \mathrm{~km}$ around Barcelona (see Fig. 3) and on 23000 grid cells in the case of the radar data. The precipitation rate statistics were based on an hourly model output for 900 grid cells during a period of $24 \mathrm{~h}$ for the model simulations and in the case of the radar, on hourly data for 23000 grid cells during the same period of $24 \mathrm{~h}$. The statistical summary includes the overall average and the average of the 5 most extreme values. Table 2 shows the accumulated precipitation and maximum precipitation rates derived from rain gauge observations stations in the surroundings of Barcelona.

Considering the numerically calculated average of the 24-h accumulated precipitation, the MRF scheme predicted a larger value compared to the other PBL schemes. The ETA scheme predicted the lowest average 24-h accumulated precipitation. Nevertheless, the average of the 5 most extreme 
Table 1. Statistical summary of the quantitative precipitation distribution produced by the numerical simulation and recorded by the radar data for 14 September 1999

\begin{tabular}{lcccc}
\hline & \multicolumn{2}{c}{ Overall average } & \multicolumn{2}{c}{ Average of 5 most extreme events } \\
\hline & $\begin{array}{c}\text { Accum. Precip. } \\
(\mathrm{mm})\end{array}$ & $\begin{array}{c}\text { Precip. Rate } \\
(\mathrm{mm} / \mathrm{h})\end{array}$ & $\begin{array}{c}\text { Accum. Precip. } \\
(\mathrm{mm})\end{array}$ & $\begin{array}{c}\text { Precip. Rate } \\
(\mathrm{mm} / \mathrm{h})\end{array}$ \\
\hline MRF & 23 & 0.94 & 134 & 50 \\
BLA & 22 & 0.90 & 120 & 55 \\
ETA & 18 & 0.77 & 131 & 59 \\
Radar & 13 & 0.52 & 182 & 98 \\
\hline
\end{tabular}

precipitation rates shows a different result. Here, the ETA scheme gives the largest value followed by the BLA and finally, the MRF scheme. The average of the 5 most extreme accumulated precipitation values and the 5 most extreme precipitation rates as predicted by the various PBL schemes were comparable to the highest observed rain gauge accumulated precipitation values and rates (see Table 2). From the comparison of the accumulated precipitation and the precipitation rate, one can conclude that MM5 produced extreme precipitation amounts comparable to the amounts recorded in observations.

\section{Sensitivity analysis of the PBL variables and pro- cesses}

According to the results discussed in the previous section, the numerical simulation using the MRF scheme yielded more precipitation than the numerical simulations using the ETA and the BLA schemes. The numerical simulation using the ETA scheme predicted the smallest amount of precipitation. However, an analysis of the most extreme cases showed that the simulation using the ETA scheme predicted the largest precipitation rates. This section discusses the reasons for these differences in terms of the role played by the turbulent transport calculated by each specific PBL scheme and the influence of these schemes on the precipitation processes and calculated fields. Since the largest precipitation differences occurred between the simulations using the MRF and ETA schemes, only these two schemes will be considered in this section. The selected variables used to analyze the various aspects of the PBL parameterizations in the modeling of the convective cloud systems are the surface fluxes, the vertical distribution of potential temperature and moisture, the mixing efficiency and the CAPE. The discussion of the above-mentioned PBL variables and processes is mainly focused over sea just off the coast of Northeast Spain were the convective systems were more intense (see Figs. 3 and 6).

\subsection{Surface sensible and latent heat fluxes}

Table 3 shows the average surface sensible ( $\mathrm{SH})$ and latent heat fluxes (LE) calculated by the MRF and ETA schemes. These average values were derived from 1-hourly model data
Table 2. Average values of the observed precipitation for 14 September 1999. The exact position of the rain gauge stations is shown in Fig. 3.

\begin{tabular}{lcc}
\hline & Acc. Precip. & Maximum Precip. rate \\
\hline Clariana & 143 & 56 \\
Villasar & 116 & 52 \\
Manresa & 86 & 41 \\
Fabra & 63 & 55 \\
Reus & 47 & 18 \\
La Seu d'Urgell & 43 & 10 \\
\hline
\end{tabular}

Table 3. Average values of the surface fluxes and cloud variables calculated by the numerical model for 14 September 1999 . The CAPE is calculated up to a level of $4 \mathrm{~km}$.

\begin{tabular}{lcccc}
\hline & $\mathrm{LE}\left(\mathrm{W} / \mathrm{m}^{2}\right)$ & $\mathrm{SH}\left(\mathrm{W} / \mathrm{m}^{2}\right)$ & $\mathrm{CAPE}(\mathrm{J} / \mathrm{kg})$ & $\mathrm{LCL}(\mathrm{m})$ \\
\hline MRF & 195 & 21 & 220 & 573 \\
ETA & 171 & 19 & 339 & 434 \\
\hline
\end{tabular}

for 8 points over sea (see Fig. 3) on 14 September 1999. The LE was approximately one order of magnitude larger than the SH. The larger values of LE calculated by the MRF scheme might partly explain the larger average accumulated precipitation as predicted by this scheme, since more moisture is transported from the sea surface into the PBL. However, when Romero et al. (1997) and Ramis (1998) investigated the role of the LE in the development and maintenance of convective systems over the Northeast of IP, they found that the LE from sea surface into the atmosphere had little impact on the simulated precipitation amounts. Therefore, it is doubtful whether the larger LE as predicted by the MRF scheme contributed to the enhanced calculated precipitation.

\subsection{Vertical distribution of temperature and moisture}

We will now discuss the vertical heat and moisture transport from the surface layer to the free troposphere by the boundary layer scheme. Figure 10 shows the vertical cross sections 
(a)

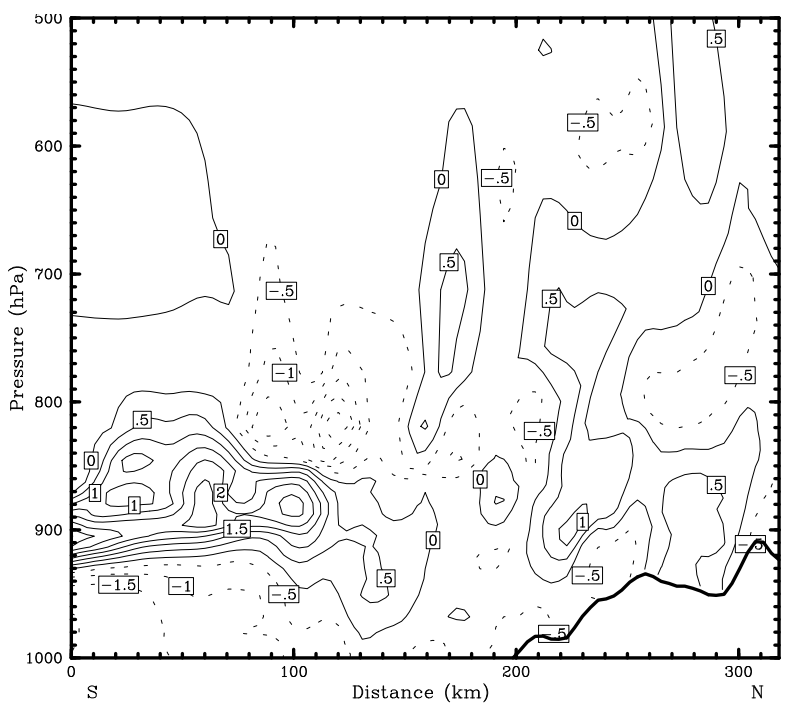

(b)

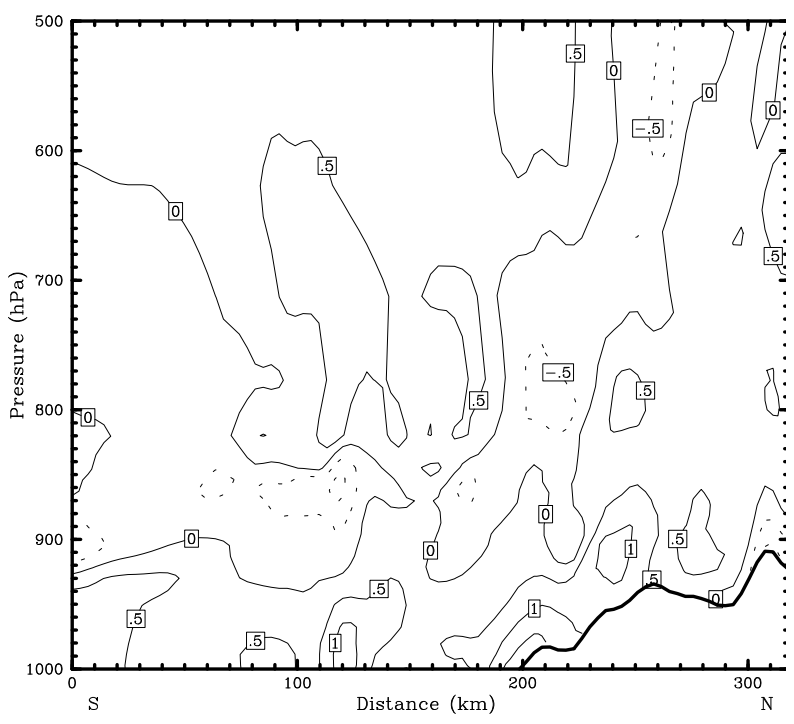

Fig. 10. Vertical cross sections of the potential temperature differences $(\mathrm{K})$ and water vapor mixing ratio differences $(\mathrm{g} / \mathrm{kg})$ for 19 September 1999 at 15:00 UT. Orientation of the cross sections is shown in Fig. 3. Both show intervals of 0.5 units. The thick line represents the topography. (a) Specific humidity difference (MRF- ETA schemes), (b) Potential temperature difference (MRFETA schemes).

of the water vapor mixing ratio differences (Fig. 10a) and potential temperature differences (Fig. 10b) for 14 September 1999, 15:00 UTC. The differences are calculated by subtracting the model results using the MRF boundary layer scheme to the model results using the ETA boundary layer scheme. At that time the air mass which fed the PBL of the convective systems at 19:00 UTC was situated over the sea. The orientation of the cross section (see the line from $\mathrm{S}$ to $\mathrm{N}$ at Fig. 3) was parallel to the mean surface wind and therefore approximately perpendicular to the coast. Air masses over sea and land are considered in the vertical cross sections. The vertical cross sections represent an average of an area $150 \mathrm{~km}$ perpendicular to the horizontal axis. In both cross sections the val- ues calculated by the MRF scheme were taken as reference values. The calculated values by the ETA scheme were subtracted from these reference values, in order to obtain moisture and potential temperature differences.

According to Fig. 10a the MRF scheme over sea predicted a drier lower part of the PBL with differences of up to $1.5 \mathrm{~g} \mathrm{~kg}^{-1}$ and a more humid upper part of the PBL (layer from $940 \mathrm{hPa}$ up to $830 \mathrm{hPa}$ ) with differences of up to $3 \mathrm{~g} \mathrm{~kg}^{-1}$. Over land the water vapor mixing ratio differences are smaller. Figure $10 \mathrm{~b}$ shows that the MRF PBL scheme over sea predicted a warmer lower part of the PBL (up to $940 \mathrm{hPa}$ ) with differences of up to $1^{\circ} \mathrm{C}$ and a slightly colder upper part of the PBL (layer from $940 \mathrm{hPa}$ up to $830 \mathrm{hPa}$ ). Over land the MRF scheme also predicted a warmer lower layer up to a much higher atmospheric level, and superimposed upon it a level with lower potential temperatures than the ETA PBL scheme. In their hurricane case, Braun and Tao (2000) also showed that the MRF scheme produced a drier and warmer lower part of the PBL, and a colder and more humid part of the upper part of the PBL than did the other schemes.

The different vertical distribution of the moisture and temperature is due to the fact that the MRF scheme uses a nonlocal parameterization of the PBL, whereas the ETA scheme uses a local parameterization of the PBL. As stated in Sect. 3, the MRF scheme accounts for processes such as the entrainment of air from the free atmosphere which can contribute to enhance the mixing and vertical transport in the PBL.

The moisture and potential temperature differences at $870 \mathrm{hPa}$ are also related to a difference in PBL height as predicted by the MRF and ETA schemes. Due to the enhanced mixing the PBL height predicted by the MRF scheme was higher than the PBL height predicted by the ETA scheme. This difference in PBL height is reflected in the average LCL as depicted in Table 3, where MRF showed the highest LCL. According to Stull (1999), the LCL is an appropriate reference for the PBL height in severe convective circumstances. It was this difference in PBL height that caused the relatively large differences in temperature and moisture content around $870 \mathrm{hPa}$ as shown in Fig. 10. For this cross section the level of $870 \mathrm{hPa}$, is probably below the PBL top for the MRF scheme and above the PBL top for the ETA scheme. Therefore, relatively cold and moist PBL air is still present at $870 \mathrm{hPa}$ as calculated by the MRF scheme, whereas the ETA scheme calculates that relatively warm and dry free atmospheric air at a level of $870 \mathrm{hPa}$.

\subsection{Mixing efficiency}

To compare the mixing efficiency of the MRF and ETA schemes, we investigated the vertical distribution of the total water content $(\mathrm{Rt})$ and the equivalent potential temperature $\left(\theta_{\mathrm{e}}\right)$. These are conserved variables under adiabatic processes regardless of the state of saturation of the air parcel; this makes them useful for the study of diabatic processes such as atmospheric mixing (Stull, 1999). Figure 11 shows an idealized conserved variable diagram for a standard atmosphere 


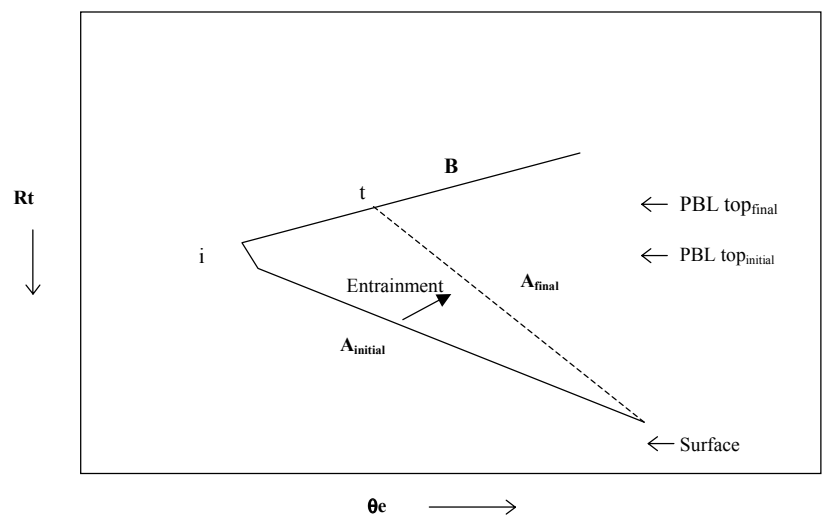

Fig. 11. Sketch of an idealized conservative diagram $\left(\theta_{\mathrm{e}}\right.$ and $\left.\mathrm{Rt}\right)$ which shows the effect of entrainment at the top of the PBL. $A_{\text {initial }}$ is the initial mixing line, $\mathrm{A}_{\mathrm{final}}$ is the final mixing line, $i$ marks the initial position of the PBL top and $t$ marks the final PBL top; B marks the line segment representing the free atmosphere.

with $\theta_{\mathrm{e}}$ plotted against Rt. The solid line represents the initial situation $\left(\mathrm{A}_{\text {initial }}\right.$ and $\left.\mathrm{B}\right)$ and $i$ represents the initial PBLtop. According to Betts (1985), this solid line consists of two important segments. The line segment $\left(\mathrm{A}_{\text {initial }}\right)$, from the surface up to the PBL top, connects the thermodynamic state of an air parcel at surface level (characterized by relatively high $\theta_{\mathrm{e}}$ and high Rt) to the thermodynamic state of an air parcel at the top of the PBL (characterized by relatively low $\theta_{\mathrm{e}}$ and low $\mathrm{Rt}$ ). The position along the mixing line indicates the final mixture of each original air parcel. Therefore, this line is called the mixing line. The line segment from the PBL top ( $i$ ) up into the free atmosphere (line B) shows an increase in $\theta_{\mathrm{e}}$ due to an increase of the potential temperature with height. As a result of entrainment of free atmospheric air into the PBL, the PBL height $(t)$ increases and the thermodynamic properties of the air parcel are modified along the line segment representing the free atmosphere, since free atmospheric air is mixed into the PBL. Therefore, the slope of the mixing line gradually becomes steeper as long as the PBL height grows. The arrow indicates in which direction the mixing line changes as a result of entrainment. The dashed line $\left(\mathrm{A}_{\text {final }}\right)$ reflects the new orientation of the mixing line due to entrainment and $t$ represents the final PBL top.

Figure 12 shows a conserved variable diagram for the Rt and $\theta_{\mathrm{e}}$ vertical distribution as calculated by the MRF and ETA schemes. The diagram was derived after averaging 8 points over sea (see Fig. 3) during 24 h (192 vertical profiles). Both schemes show a mixing line in the lower part of the atmosphere. However, a comparison of the two mixing lines shows that the mixing line predicted by the MRF scheme extended to a higher level $(800 \mathrm{hPa})$ than the one predicted by the ETA scheme $(830 \mathrm{hPa})$. The latter parameterizations show very little variation at the equivalent potential temperature of $318.5 \mathrm{~K}$ between $830 \mathrm{hPa}$ to $800 \mathrm{hPa}$, which indicates that precipitation is taking place between these two levels.

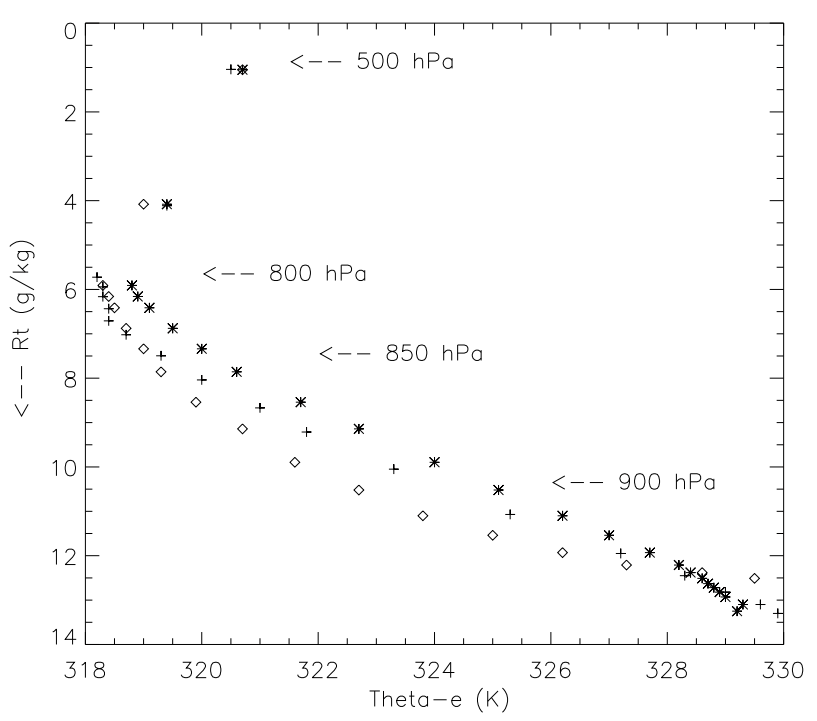

Fig. 12. Conserved variable diagram of the total water content (Rt) and the $\theta_{\mathrm{e}}$ for a 24 -h average vertical profile of 192 profiles over the sea for 14 September 1999 , as predicted by the MRF (*), the ETA $(+)$, and the BLA $(\diamond)$ schemes.

Furthermore, the mixing line predicted by the MRF scheme showed a steeper slope. According to Fig. 11, these differences can be attributed to the higher PBL growth, mainly due to the description of entrainment in the MRF scheme, resulting in enhanced mixing compared to the ETA scheme.

The enhanced vertical mixing calculated by the MRF scheme leads to larger amounts of precipitation. More vigorous mixing resulted in a larger flux of moisture from the surface up to the cloud layer. Consequently, more latent heat is released inside the cloud due to condensation. These results disagree partially with the previous sensitivity analysis of PBL schemes done by Braun and Tao (2000). They concluded that due to the excessively deep vertical mixing and drying of the lower PBL produced by the MRF scheme, the MM5 simulation using the MRF parameterization simulates the weakest hurricane (in terms of wind speed). However, we have to emphasis that a hurricane situation is not in every aspect comparable with the specific case in this research. High wind speeds have a significant effect on the surface latent heat flux. These wind speeds were not available in this specific case.

\subsection{Analysis of the Convective Available Potential Energy (CAPE)}

As mentioned in the previous section, the numerical simulation that described the PBL using the MRF scheme yielded the most widespread precipitation. However, in the most extreme events, the ETA scheme produced the highest precipitation rates. This can possibly be explained in terms of the convective available potential energy (CAPE), namely, the CAPE is proportional to the total amount of kinetic energy that an ascending air parcel gains from the difference 
between the temperature of the environment and the temperature of the air parcel. The CAPE reflects the intensity of vertical motions of individual air parcels and is therefore a variable that indicates the strength of convective systems. In other words, high CAPE values are indicative of possible high precipitation rates. Besides the CAPE the precipitation significantly depends on the availability of environmental moisture, especially in the lower part of the atmosphere. From Fig. 5 we can conclude that in this specific case, there is enough moisture available in the lower part of the atmosphere (high $\theta_{e}$ values). Figure $10 \mathrm{~b}$ shows that there is only a minor difference between the run based on the MRF and the run based on the ETA scheme. In other words, both runs show comparable and a sufficient moisture content to develop deep convection with high precipitation rates.

Table 3 shows the average CAPE values as predicted by the MRF and ETA schemes. These average values were derived from the same vertical profiles as those used in Fig. 12. The CAPE was calculated up to a level of $4 \mathrm{~km}$. This relatively low level of $4 \mathrm{~km}$ was selected in order to exclude upper level differences between the different numerical simulations and to focus mainly on the values of CAPE near the PBL. As Table 3 shows, the ETA scheme predicted higher average CAPE values in the lowest $4 \mathrm{~km}$ than did the MRF scheme. According to Carlson and Ludlam (1968) and Lanicci (1985) this difference in average CAPE values was probably a result of the difference in inversion strength at the top of the PBL. These authors showed that convection is often postponed or "capped" due to a stronger capping inversion. This results in a suppressed exchange of heat and moisture with the free atmosphere and therefore allows temperature and water vapor mixing ratio values to build up in the PBL. The CAPE values will increase due to an increase of temperature and water vapor mixing ratio values. The convective cells that finally break through the inversion have a greater potential for becoming severe due to stronger updrafts and are likely to undergo explosive growth as a result of the higher CAPE values. The ETA scheme did indeed calculated higher water vapor mixing ratios between 930 and $1000 \mathrm{hPa}$ (see Fig. 10a). The temperature, however, was slightly lower than in the MRF scheme (see Fig. 10b).

\section{Conclusions}

A severe convective precipitation event that occurred over Northeast Spain was studied by means of the meso-scale numerical model MM5 and surface and radar observations. The role of the planetary boundary layer (PBL) schemes in the numerical simulations of severe convective systems is evaluated. This severe convective precipitation event was characterized by a typical sea level pressure distribution that resulted in enhanced transport of warm and moist Mediterranean air to the area of Northeast Spain. The steep orography parallel to the coast forced the air to ascend, which triggered extreme amounts of precipitation.
The following PBL schemes are discussed: the MediumRange Forecast (MRF) scheme, the High-resolution Blackadar (BLA) scheme and the Eta-Mellor-Yamada (ETA) scheme. These parameterizations were selected because they are based on different physical assumptions to describe the turbulent transport in the PBL. In addition, they are widely used in other meso-scale and general circulation models. The ETA scheme uses a local approach to calculate the heat and moisture fluxes, whereas the MRF and BLA schemes use a nonlocal approach. Due to the nonlocal approach assumed in the MRF and BLA parameterizations, the vertical transport of momentum, heat and water vapor are expected to reach higher levels than the ones calculated by the ETA parameterization.

Comparison of the precipitation evolution using the numerical simulations results and rain gauge data, showed that all three numerical simulations, each using a different PBL scheme, calculated the maximum precipitation at times that differ from those observed. In particular, all the numerical simulations show the maximum precipitation in the morning (around 08:00 UTC), whereas the rain gauge stations measured most of the precipitation during the evening (around 20:00 UTC). However, the three numerical simulations showed a similar spatial distribution that was in close agreement with the pattern distribution observed by the radar. From the average of the 5 most extreme amounts of 24-h accumulated precipitation and the average of the 5 most extreme rates of precipitation one can conclude that the numerical model was able to predict values comparable to the rain gauge observations.

The precipitation fields calculated by the various PBL schemes showed that the MRF scheme tends to produce more widespread precipitation with a higher average accumulated precipitation amount than do the BLA and ETA schemes. The ETA scheme yields less widespread precipitation with a lower average accumulated precipitation than the other PBL schemes. However, the ETA scheme tended to produce more extreme precipitation rates. Consequently, the amount of precipitation and the precipitation rates produced by convective systems were sensitive to the various PBL schemes.

The difference in the amount of precipitation calculated by the MRF and ETA schemes is connected with the different description of the vertical mixing processes. The deeper vertical transport of heat and water vapor produced by MRF led to a more active convective precipitation than did the ETA scheme. Due to this enhanced mixing, the MRF scheme predicted a deeper PBL with a drier and warmer lower part of the PBL and a cooler and more moisture upper part of the PBL than did the ETA scheme. This pattern occurred particularly over sea. According to the back trajectory analysis, the sea was the origin area where the convective systems developed and intensified. Due to the drier lower part of the atmosphere, as predicted by the MRF scheme, the surface latent heat fluxes were enhanced over the sea in the case of the MRF scheme.

The discussion in terms of the conservative variables $\theta_{\mathrm{e}}$ and the total water content showed that the MRF scheme 
produces more vigorous mixing. Due to this enhanced mixing calculated by the MRF scheme, moisture was probably more efficiently transported up to the higher atmospheric levels. Condensation of this extra amount of water vapor probably resulted in more latent heat release and therefore a stronger development of clouds and convective showers. Consequently, more widespread and larger 24-h accumulated precipitation and average precipitation rate was found using the MRF scheme. Furthermore, the MRF scheme yielded a weaker capping inversion at the top of the PBL. Therefore, thermals or eddies could more easily break through this inversion and reach the LFC, leading to the more widespread development of convective showers.

The highest precipitation rates during extreme events calculated by the ETA scheme are induced by the largest values of CAPE. The reason for this is the stronger capping inversion produced by the ETA scheme. Fewer thermals could break through this capping inversion, and consequently the CAPE levels increased due to a suppressed transport of moisture and heat to the free atmosphere.

Acknowledgements. The authors are grateful to W. van den Berg for discussing the synoptic situation; to the National Meteorological Institute from Spain (INM,Barcelona) for supplying the radar data and to the Department of Meteorology and Astronomy of the University of Barcelona (Spain) for providing the rain gauge data. We are grateful to one anonymous reviewer for his/her suggestions and careful reading of the paper.

Topical Editor O. Boucher thanks two referees for their help in evaluating this paper.

\section{References}

Anthes, R. A.: A cumulus parameterization scheme utilizing a onedimensional cloud model, Mon. Wea. Rev., 105, 270-286, 1977.

Atkinson, B. W.: Meso-scale atmospheric circulations, London Academic Press, 95, 1981.

Bader, M. J., Forbes, G. S., Grant, R. B. E., Lilly, R. B. E., and Waters, A. J.: Images in weather forecasting: A practical guide for interpreting satellite and radar imagery, Press Syndicate of the University of Cambridge, 499, 1995.

Bechtold, P. and Bazile, E.: The 12-13 November 1999 flash flood in souther France, Atmos Res., 56, 171-189, 2001.

Betts, A. K.: Mixing line analysis of clouds and cloudy boundary layers, J. Atmos. Sci., 42, 2751-2763, 1985.

Blackadar, A. K.: Modeling the nocturnal boundary layer, Preprints, Third Symp. On Atmospheric Turbulence, Diffusion, and Air Quality, Raleigh, NC, Amer. Meteor. Soc., 46-49, 1976.

Blackadar, A. K.: High resolution models of the planetary boundary layer, Advances in Environmental Science and Engineering, edited by Pfafflin, J. and Ziegler, E., Vol. 1, No. 1, Gordon and Breach, 50-85, 1979.

Bougeault, P., Binder, P., Buzzi, A., Dirks, R., Houze, R., Kuettner, J., Smith, R. B., Steinacker, R., and Volkert, H.: The MAP special observing period, Bull. Am. Meteorol. Soc., 82, 433-462, 2001

Bougeault, P., Houze, R., Rotunno, R, and Volkert, H.: Editorial, Q. J. R. Meteorolo. Soc., 129, 3451-343, 2003.
Braun, S. A. and Tao, W.: Sensitivity of High-Resolution Simulations of Hurricane Bob (1991) to Planetary Boundary Layer Parameterizations, Mon. Wea. Rev. 128, 3941-3961, 2000.

Carlson, T. N. and Ludlam, F. H.: Conditions for the occurrence of severe local storms, Tellus, 20 , 203-266, 1968.

Deardorff, J. W.: The countergradient heat flux in the lower atmosphere and in the Laboratory, J. Atmos. Sci., 23, 503-506, 1966.

Dudhia, J.: A nonhydrostatic version of the Penn State-NCAR mesoscale model: Validation tests and simulation of an Atlantic cyclone and cold front, Mon. Wea. Rev., 121, 1493-1513, 1993.

Dudhia, J.: A multi-layer soil temperature model for MM5, Preprints, The Sixth PSU/NCAR Mesoscale Model Users' Workshop, 22-24 July 1996, Boulder, Colorado, 49-50, 1996.

Dudhia, J., Gill, D., Guo, Y.-R., Manning, K., Wang, W., and Chiszar, J.: PSU/NCAR Mesoscale Modeling System Tutorial Class Notes and User's Guide: MM5 Modeling System Version 3, 2000.

Ferretti, R., Low-Nam, S., and Rotunno, R.: Numerical simulation of the Piedmont flood of 4-6 November 1994, Tellus, 52A, 162 180, 2000.

Ferretti, R., Paolucci, T., Giuliani, G., Cherubini, T., Bernardini, L., and Visconti, G.: Varification of high-resolution real-time forecsts over the Alpine region during the MAP SOP, Q. J. R. Meteorl Soc., 129, 587-607, 2003.

Font, I.: Climatologia de Espana y Portugal, Instituto Nacional de Meteorologia, (in Spanish), 296, 1983

Grell, G. A., Dudhia, J., and Stauffer, D. R.: A description of the fifth-generation Penn State/NCAR Mesoscale Model (MM5), NCAR Tech. Note NCAR/TN-398 +STR, 122, 1995.

Hong, S. H. and Pan, H. L.: Nonlocal boundary layer vertical diffusion in a medium-range forecast model, Mon. Wea. Rev., 124, 2322-2339, 1996

Janjic, Z. I.: The Step-Mountain Eta coordinate Model: Further Developments of the Convection Viscous Sublayer, and Turbulence Closure Schemes, Mon. Wea. Rev., 122, 927-945, 1994.

Kuo, H. L.: Further studies of the parameterization of the influence of cumulus convection on large-scale flow, J. Atmos. Sci., 31, 1232-1240, 1974.

Lanicci, J. M.: An operational procedure using elevated mixedlayer analyses to predict severe storm outbreaks, Preprints 14th Conference on Severe Local Storms, Indianapolis, USA, 406409, 1985.

McGinley, J.: Nowcasting mesoscale phenomena, Mesoscale Meteorology and Forecasting, 657-688, 1986.

Oncley, S. P. and Dudhia, J.: Evaluation of surface fluxes from MM5 using observations, Mon. Wea. Rev., 123, 3344-3357, 1995.

Priestely, C. H. B. and Swinbank, W. C.: Vertical transport of heat by turbulence in the Atmosphere. Proc. R. Soc., A189, 543-561, 1947.

Ramis, C., Llasat, M. C., Genoves, A., and Jansa, A.: The October1987 floods in Catalonia: Synoptic and mesoscale mechanisms, Meteorol. Appl., 1, 337-350, 1994.

Ramis, C., Romero, R., Homar, V., Alonso, S., and Alorcon, M.: Diagnosis and Numerical Simulation of a Torrential Precipitation Event in Catalonia (Spain), Meteorol. Atmos. Phys., 69, 1-21, 1998.

Romero, R., Ramis, C., and Alonso, S.: Numerical simulation of an extreme rainfall event in Catalonia: Role of orography and evaporation from the sea, Quart. J. Roy. Meteor. Soc., 123, 537$559,1997$. 
Romero, R., Guijarro, J. A., Ramis, C., and Alonso, S.: A 30 year (1964-1993) daily rainfall data base for the Spanish mediterranean regions: First exploratory study, Int. J. Climatol., 18, 541560, 1998.

Romero, R., Doswell, C. A., and Ramis, C.: Mesoscale Numerical Study of two Cases of Longlived Quasi-Stationary Convective Systems over Eastern Spain, Mon. Wea. Rev., 128, 3731-3751, 2000.

Ryzhkov, A. and Zrnic, D. S.: Precipitation and attenuation measurements at a 10-cm wavelength, J. Appl. Meteor., 34, 21212134, 1995.

Saunders, F., Göber, M., and Chalcraft, B.: The exceptional rainfall event of 11 and 12 October 2000 in Kent and Sussex, as observed and as forecast by the Met Office Mesoscale Model, Weather, 56, 360-367, 2001.
Stull, R. B.: An Introduction to Boundary Layer Meteorology, Kluwer Academic Publisher, 670, 1999.

Troen, I. B. and Mahrt, L.: A simple model of the atmospheric boundary layer, sensitivity to surface evaporation, BoundaryLayer Meteor., 37, 129-148, 1986.

Weisman, M. L. and Klemp, J. B.: Characteristics of isolated convective storms, Mesoscale Meteorology and Forecasting, 331358, 1986.

Zhang, D. L. and Anthes, R. A.: A high-resolution model of the planetary boundary layer - Sensitivity tests and comparisons with SESAME-79 data, J. Appl. Meteor., 21, 1594-1609, 1982. 